\title{
The Inhibition of Mild Steel Corrosion in Sulfuric Acid by New Dapsone Derivatives
}

\author{
M.P. Chakravarthy, K.N. Mohana* and C.B. Pradeep Kumar
}

Department of Studies in Chemistry, University of Mysore, Manasagangothri, Mysore 570 006, India

*Author for correspondence: drknmohana@gmail.com

\begin{abstract}
Dapsone derivatives Viz., 4, 4'-sulfonylbis( $\mathrm{N}-((1 \mathrm{H}-$ pyrrol-2-yl)methylene)aniline) (SBPMA) and 2-dimethylamino-5-[(4-\{4[(4-dimethylamino-benzylidene)-amino]-benzenesulfonyl\}-phenylimino)-methyl]-benzene (DBBPB), a new class of corrosion inhibitors have been synthesized and their corrosion inhibition efficiency on mild steel in $0.5 \mathrm{M} \mathrm{H}_{2} \mathrm{SO}_{4}$ was investigated by mass loss, Tafel polarization and AC impedance measurements. Potentiodynamic polarization studies showed that, these compounds behave as mixed type of corrosion inhibitors. The adsorption process was found to obey Langmuir isotherm model. Electrochemical impedance spectroscopy (EIS) studies revealed that polarization resistance $\left(R_{\mathrm{P}}\right)$ increases and double layer capacitance $\left(C_{\mathrm{dl}}\right)$ decreases as the concentration of the inhibitors increases. Various thermodynamic parameters for the adsorption of inhibitors on mild steel were computed and discussed. FTIR, EDX and SEM analyses were performed to study the film persistency of the inhibitors.
\end{abstract}

\section{Indexing terms/Keywords}

Dapsone derivatives; Mild steel corrosion; Electrochemical techniques; Energy dispersive X-ray spectroscopy (EDX); Thermodynamic parameters.

\section{Council for Innovative Research}

Peer Review Research Publishing System

Journal: Journal of Advances in Chemistry

Vol. 10, No. 3

editorjaconline@gmail.com 


\section{INTRODUCTION}

Mild steel (MS) is an alloy of iron, carbon and several other elements, which hardens above its critical temperature, and is a class of strong, tough and low cost steel with an excellent mechanical property. It has good physical and chemical properties such as toughness, welding, stamping and cutting performance. It is the most extensively used alloy in a wide spread spectrum of many industrial units for structural, instrumental and automobile applications. But it is highly susceptible for corrosion in humid air especially in acidic media [1]. In order to prevent corrosion, the primary strategy adopted is to isolate the metal from corrosive media. Amongst the various methods available, the use of inhibitors is one of the most practical and economical methods for protection against corrosion. The use of inhibitors for the corrosion inhibition of MS is the subject of tremendous technological importance due to the increased industrial applications of MS and other related materials especially in acid media [2]. Therefore, a wide variety of corrosion inhibitors ranging from rare earth elements [3] to organic compounds [4-7] have been used. There is a continuing effort to find corrosion inhibitors that exhibit greater effect with smaller quantity in the corrosive media. This is a challenging problem in the steel industry because corrosion over MS surfaces affects long term industrial projects. The performance of corrosion inhibitors based on organic compounds containing nitrogen, sulphur and oxygen atoms shows promising results. The corrosion inhibition property of inhibitors depends on their molecular structures, planarity and the lone pairs of electrons present on the hetero atoms, which determine the adsorption of these molecules on the metallic surfaces. Corrosion inhibitors block the active sites and enhance the adsorption process, thus decreasing the rate of dissolution and extending the life span of the equipment $[8,9]$.

The use of organic compounds as corrosion inhibitors is the main choice in various industrial processes such as acid pickling of steels, scale removal in metallurgy, acid cleaning of boilers and oil-well acidizing. Generally, a variety of organic compounds containing heteroatoms such as $\mathrm{O}, \mathrm{N}, \mathrm{S}$ and multiple bonds in their structure are of particular interest as they give better inhibition efficiency than those containing $\mathrm{N}$ or $\mathrm{S}$ alone [10,11]. Compounds rich in heteroatoms can be regarded as environmental friendly inhibitors because of their characteristic strong chemical activity and low toxicity [12]. The adsorption characteristics of organic molecules are also affected by size, electron density at the donor atoms and orbital character of the donating electrons [13-16]. Organic compounds containing hetero atoms in the functional groups, pi-electron in triple or conjugated double bonds and presence of aromatic rings in their structure are the major adsorption centers and are usually good inhibitors [17]. Several nitrogen, oxygen and sulphur containing heterocyclic compounds such as indole derivatives [18], acetyl pyridine derivatives [19], thiosemicarbazone derivatives [20], sulphonamide compounds [21], thiadiazoles derivatives [22], imidazole derivatives [23], triazoles [24], pyrazole derivatives [25], pyridazine derivatives [26] and triazines [27] have been reported as anticorrosion substances in acid media.

This study reports the inhibitive effect of two newly synthesized dapsone derivatives such as 4,4 '-sulfonylbis( $N$ $((1 \mathrm{H}$-pyrrol-2-yl)methylene)aniline) (SBPMA) and 2-dimethylamino-5-[(4-\{4-[(4-dimethylamino-benzylidene)-amino]benzenesulfonyl\}-phenylimino)-methyl]-benzene (DBBPB) on the corrosion of MS in $0.5 \mathrm{M} \mathrm{H}_{2} \mathrm{SO}_{4}$ using mass loss and electrochemical techniques. The experimental results were discussed with various activation and adsorption thermodynamic parameters. The passive film formed on the metal surface was characterized by FTIR, EDX and SEM studies. Further, the inhibition performances of the two derivatives have been compared and discussed.

\section{EXPERIMENTAL}

\subsection{Materials}

\subsubsection{Mild steel specimen preparation}

MS specimens used in the present study having the following chemical compositions (in wt \%) : C $-0.051 ; \mathrm{Mn}$ 0.179; Si - 0.006; P - 0.005; S - 0.023; Cr - 0.051; Ni - 0.05; Mo - 0.013; Ti - 0.004; Al - 0.103; Cu - 0.050; Sn - 0.004; B $0.00105 ; \mathrm{Co}-0.017 ; \mathrm{Nb}-0.012 ; \mathrm{Pb}-0.001$ and the remainder iron. For all experiments, MS specimens of dimension $1 \mathrm{~cm}$ $\times 1 \mathrm{~cm} \times 0.1 \mathrm{~cm}$ were used. The specimens were mechanically well abraded with different grades SiC (1200 - 1600) emery papers, degreased with benzene, washed with triply distilled water and finally dried. All the solvents and chemicals used were of AR grade and used as such. Doubly distilled water was used in the preparation of the various concentrations of test solutions.

\subsubsection{Synthesis of inhibitors}

SBPMA was synthesized by dissolving $0.62 \mathrm{~g}(2.5 \mathrm{mmol})$ of dapsone $\left(\mathrm{C}_{12} \mathrm{H}_{12} \mathrm{~N}_{2} \mathrm{O}_{2} \mathrm{~S}\right.$, Mol. Wt. 248.30) in $15 \mathrm{~mL}$ of ethanol in a round bottom flask. To this $0.47 \mathrm{~g}(5 \mathrm{mmol})$ of pyrrole-2-carboxaldehyde $\left(\mathrm{C}_{5} \mathrm{H}_{5} \mathrm{NO}\right.$, Mol. Wt. 95.10$)$ in $15 \mathrm{~mL}$ ethanol was mixed and refluxed for $6 \mathrm{~h}$ at $60^{\circ} \mathrm{C}$ in presence of glacial acetic acid, and then the solution was concentrated using rotary evaporator and kept for dry in vacuum. DBBPB was synthesized by dissolving $0.62 \mathrm{~g}(2.5 \mathrm{mmol})$ of dapsone in $15 \mathrm{~mL}$ of ethanol in a round bottom flask. To this a $0.74 \mathrm{~g}(5 \mathrm{mmol})$ of p-dimethylamino-benzaldehyde $\left(\mathrm{C}_{9} \mathrm{H}_{11} \mathrm{NO}\right.$, Mol. Wt. 149.19) dissolved in $15 \mathrm{~mL}$ of ethanol was added and refluxed for $6 \mathrm{~h}$ with stirring at $60^{\circ} \mathrm{C}$ in presence of glacial acetic acid. Then the solution was concentrated using rotary evaporator and kept for dry in vacuum and the product obtained was collected. The synthetic scheme of SBPMA and DBBPB are shown in Fig. 1. 

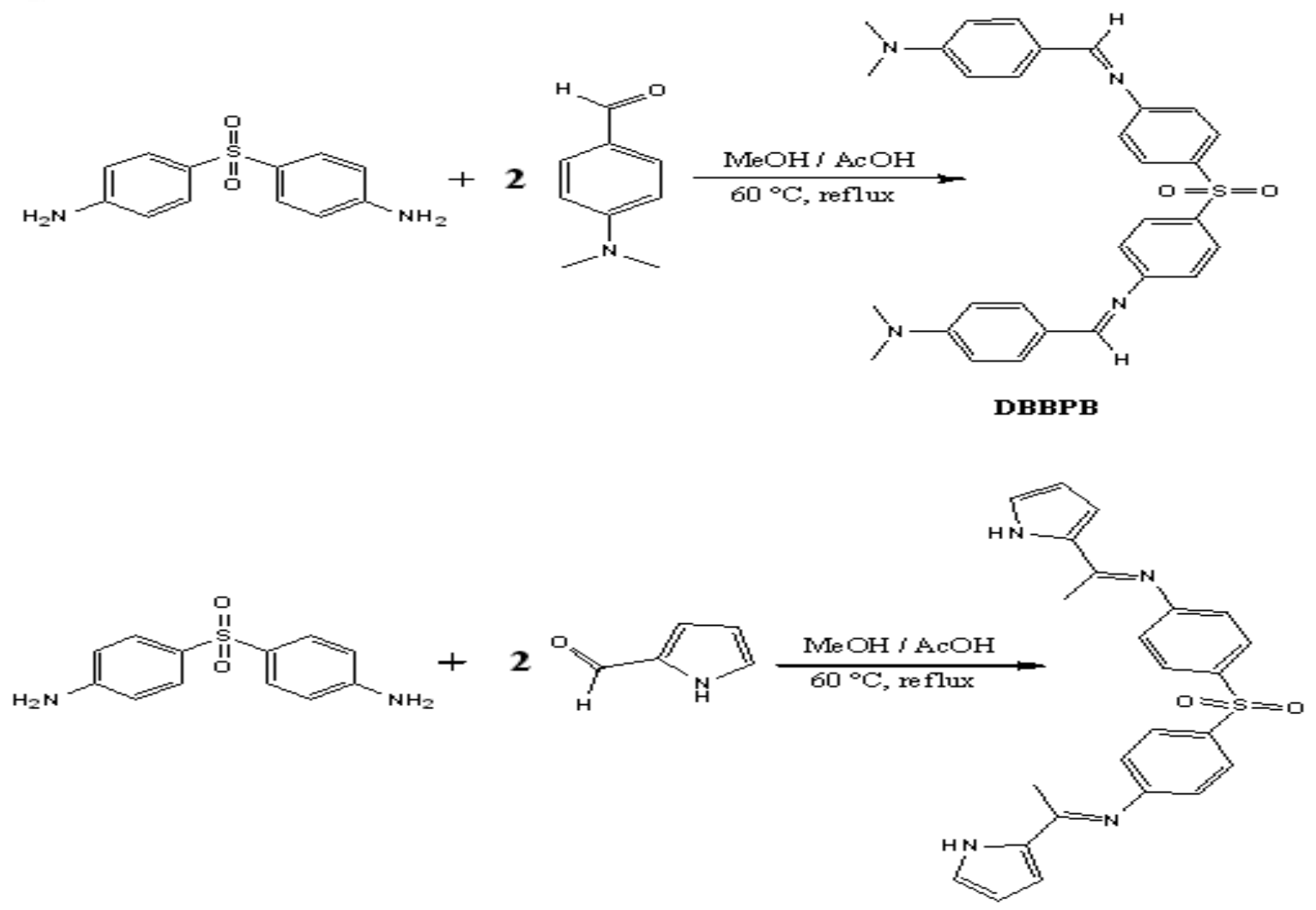

SBPNLA

Fig. 1. Synthetic schemes of SBPMA and DBBPB.

The Chemical structures of the compounds are characterized by FTIR, ${ }^{1} \mathrm{H}-\mathrm{NMR}$ and mass spectral studies. SBPMA $\left(\mathrm{C}_{22} \mathrm{H}_{18} \mathrm{~N}_{4} \mathrm{O}_{2} \mathrm{~S}\right.$, Mol. Wt. 402.47): Yield: $86 \%$, Melting Range (M. R, $\left.{ }^{\circ} \mathrm{C}\right): 202-204$. FTIR $\left(\mathrm{KBr}, \mathrm{cm}^{-1}\right): 1146\left(\mathrm{SO}_{2}\right.$ symmetric stretching), 1293 ( $\mathrm{SO}_{2}$ asymmetric stretching), $1615(\mathrm{~N}=\mathrm{C}), 1626(\mathrm{C}=\mathrm{N}) .{ }^{1} \mathrm{H}-\mathrm{NMR}(400.15 \mathrm{MHz}$, DMSO-d6) $\delta$ ppm: 8.65 (s, 2H), $8.58(\mathrm{~s}, 2 \mathrm{H}), 7.89-7.87(\mathrm{~d}, \mathrm{~J}=8.0 \mathrm{~Hz}, 4 \mathrm{H}), 7.52-7.50(\mathrm{~d}, \mathrm{~J}=7.8 \mathrm{~Hz}, 4 \mathrm{H}), 7.11-6.92(\mathrm{~d}, \mathrm{~J}=8.2 \mathrm{~Hz}, 2 \mathrm{H})$, 6.78-6.76 $(\mathrm{d}, \mathrm{J}=7.6 \mathrm{~Hz}, 2 \mathrm{H}), 6.72-6.70(\mathrm{t}, 2 \mathrm{H}) . \mathrm{MS}, \mathrm{m} / \mathrm{z}: 403(\mathrm{M}+1)$. Elemental analyses found (calculated) for $\mathrm{C}_{22} \mathrm{H}_{18} \mathrm{~N}_{4} \mathrm{O}_{2} \mathrm{~S}$ (\%): C, 65.63 (65.65): $\mathrm{H}, 4.49$ (4.51): N, 13.87 (13.92), O, 7.91 (7.95), S, 7.95 (7.97).

DBBPB $\left(\mathrm{C}_{30} \mathrm{H}_{30} \mathrm{~N}_{4} \mathrm{O}_{2} \mathrm{~S}\right.$, Mol. Wt. 510.65): Yield: $85 \%$, Melting Range (M. R, $\left.{ }^{\circ} \mathrm{C}\right): 192-196 . \mathrm{FTIR}\left(\mathrm{KBr}, \mathrm{cm}^{-1}\right)$ : $1142\left(\mathrm{SO}_{2}\right.$ symmetric stretching), 1294 ( $\mathrm{SO}_{2}$ asymmetric stretching), $1597(\mathrm{~N}=\mathrm{C}), 1639(\mathrm{C}=\mathrm{N}) .{ }^{1} \mathrm{H}-\mathrm{NMR}(400.15 \mathrm{MHz}$, DMSO-d6) $\delta \mathrm{ppm}: 3.00(\mathrm{~s}, 12 \mathrm{H}), 6.14(\mathrm{~s}, \mathrm{br}, 2 \mathrm{H}), 6.58(\mathrm{~d}, \mathrm{~J}=5.91 \mathrm{~Hz}, 2 \mathrm{H}), 6.76(\mathrm{~d}, \mathrm{~J}=8.91 \mathrm{~Hz}, 2 \mathrm{H}), 7.27(\mathrm{~d}, \mathrm{~J}=8.52 \mathrm{~Hz}$, $2 \mathrm{H}), 7.42(\mathrm{~d}, \mathrm{~J}=8.61 \mathrm{~Hz}, 2 \mathrm{H}), 7.53(\mathrm{~d}, \mathrm{~J}=8.67 \mathrm{~Hz}, 2 \mathrm{H}), 7.69(\mathrm{~d}, \mathrm{~J}=5.22 \mathrm{~Hz}, 2 \mathrm{H}), 7.78(\mathrm{~d}, \mathrm{~J}=8.49 \mathrm{~Hz}, 2 \mathrm{H}), 8.36(\mathrm{~s}, 2 \mathrm{H})$. MS, m/z: $511(\mathrm{M}+1)$. Elemental analyses found (calculated) for $\mathrm{C}_{30} \mathrm{H}_{30} \mathrm{~N}_{4} \mathrm{O}_{2} \mathrm{~S}(\%): \mathrm{C}, 70.51$ (70.56): $\mathrm{H}, 5.86(5.92): \mathrm{N}$, 10.94 (10.97), O, 6.21 (6.27), S, 6.24 (6.28). Melting range was determined by Veego Melting Point VMP III apparatus. FTIR spectra were recorded using a Jasco FTIR 4100 double beam spectrophotometer. ${ }^{1} \mathrm{H}$-NMR spectra were recorded on Bruker DRX-500 spectrometer at $400 \mathrm{MHz}$ using DMSO- $\mathrm{d}_{6}$ as solvent and TMS as an internal standard. Mass spectra were recorded by LC/MSD Trap XCT. Elemental analyses were recorded on VarioMICRO superuser V1.3.2 Elementar.

\subsection{Methodology}

\subsubsection{Mass loss measurements}

Mass loss measurements were performed by weighing cleaned and dried MS specimens before and after immersion in $0.5 \mathrm{M} \mathrm{H}_{2} \mathrm{SO}_{4}$ solutions from one to five hours in the absence and presence of various concentrations of SBPMA and DBBPB at different temperatures $\left(30-60^{\circ} \mathrm{C}\right)$. Triplicate experiments were performed in each case and the mean value of the mass loss was noted. Corrosion rate $(C R)$ in $\mathrm{mg} \mathrm{cm}^{-2} \mathrm{~h}^{-1}$ and inhibition efficiency $I E_{\mathrm{ML}}(\%)$ were calculated using the following equations:

$$
C R=\frac{\Delta M}{S t}
$$

where $\Delta M$ is the mass loss, $S$ is the surface area of the specimen and $t$ is immersion time.

$$
I E_{M L}(\%)=\frac{(C R)_{a}-(C R)_{p}}{(C R)_{a}} \times 100
$$

where $(C R)_{\mathrm{a}}$ and $(C R)_{\mathrm{p}}$ are the corrosion rates in the absence and the presence of inhibitor, respectively. 


\subsubsection{Potentiodynamic polarization measurements}

The potentiodynamic polarization studies were carried out with MS specimen as working electrode in $0.5 \mathrm{M}$ $\mathrm{H}_{2} \mathrm{SO}_{4}$ solutions with different inhibitor's concentrations $(200-500 \mathrm{ppm})$ with an exposed area of $1 \mathrm{~cm}^{2}$ and this working area was remained precisely fixed throughout the experiment. A conventional three electrode cell consisting of MS as working electrode, platinum foil as counter electrode and saturated calomel electrode as reference electrode was used. Potentiodynamic polarization studies were carried out using $\mathrm{CH}$-instrument (model CHI660D). Before each Tafel experiment, the MS electrode was allowed to corrode freely and its open circuit potential (OCP) was recorded as a function of time up to $30 \mathrm{~min}$. After this time, a steady state OCP corresponding to the corrosion potential ( $\left.E_{\text {corr }}\right)$ of the working electrode was obtained. The $I E_{\mathrm{P}}(\%)$ was calculated from corrosion currents determined from the Tafel extrapolation method using the experimental relation (3):

$$
I E_{p}(\%)=\frac{\left(I_{\text {corr }}\right)_{a}-\left(I_{\text {corr }}\right)_{p}}{\left(I_{\text {corr }}\right)_{a}} \times 100
$$

where $\left(I_{\text {corr }}\right)_{a}$ and $\left(I_{\text {corr }}\right)_{p}$ are the corrosion current density $\left(\mu \mathrm{A} \mathrm{cm}{ }^{-2}\right)$ in the absence and presence of the inhibitor, respectively.

\subsubsection{Electrochemical impedance spectroscopy (EIS)}

Electrochemical impedance measurements were carried out using the same $\mathrm{CH}$-instrument. The EIS data were taken in the frequency range $10 \mathrm{kHz}$ to $100 \mathrm{mHz}$. The double layer capacitance $\left(C_{\mathrm{dl}}\right)$ and the polarization resistance $\left(R_{\mathrm{p}}\right)$ were determined from Nyquist plots [28]. The percentage inhibition efficiency, IEEIS (\%) was calculated from $R_{\mathrm{p}}$ values using the following expression:

$$
I E_{\text {EIS }}(\%)=\frac{1 /\left(R_{p}\right)_{a}-1 /\left(R_{p}\right)_{p}}{1 /\left(R_{p}\right)_{a}} \times 100
$$

where $\left(R_{\mathrm{p}}\right)_{\mathrm{a}}$ and $\left(R_{\mathrm{p}}\right)_{\mathrm{p}}$ are polarization resistances in the absence and presence of inhibitor, respectively.

\subsubsection{FTIR, EDX and SEM studies}

The MS specimens were immersed in $0.5 \mathrm{M} \mathrm{H}_{2} \mathrm{SO}_{4}$ in the presence of inhibitors $(500 \mathrm{ppm})$ for a period of $5 \mathrm{hr}$. Then the specimens were taken out and dried. The surface adheared film was scratched carefully and its FTIR spectra were recorded using a Jasco FTIR 4100 double beam spectrometer. The surface feature of the MS specimens in the absence and presence of inhibitors was studied by energy dispersive X-ray spectroscopy (EDX) and scanning electron microscopy (model JSM-5800).

\section{RESULTS AND DISCUSSION}

\subsection{Mass loss studies}

The $C R$ and $I E_{\mathrm{ML}}(\%)$ in the absence and presence of various concentrations of SBPMA and DBBPB in $0.5 \mathrm{M} \mathrm{H}_{2} \mathrm{SO}_{4}$ solution and at different temperatures $\left(30-60^{\circ} \mathrm{C}\right)$ are presented in Table 1 . The mass loss was found to be decreased and $I E_{\mathrm{ML}}(\%)$ observed to be increased with increasing concentration of dapsone derivatives. The studied inhibitors were found to attain the maximum inhibition efficiency at $500 \mathrm{ppm}$. There is no appreciable increase in the inhibition efficiency after $5 \mathrm{hr}$ of immersion time, this is due to desorption of the inhibitor molecules from the metal surface with increasing immersion time and instability of inhibitor film on the metal surface $[29,30]$. The $I E_{M L}(\%)$ of DBBPB found to be greater than that of SBPMA.

Table 1: $C R$ and $I E_{M L}(\%)$ obtained from mass loss measurements of $M S$ in $0.5 \mathrm{M} \mathrm{H}_{2} \mathrm{SO}_{4}$ solution containing

\begin{tabular}{|c|c|c|c|c|c|}
\hline \multirow{2}{*}{$\begin{array}{c}\mathrm{T} \\
\left({ }^{\circ} \mathrm{C}\right)\end{array}$} & \multirow{2}{*}{$\begin{array}{c}\text { C } \\
\text { (ppm) }\end{array}$} & \multicolumn{2}{|c|}{ SBPMA } & \multicolumn{2}{|c|}{ DBBPB } \\
\hline & & $\begin{array}{c}C R \\
\left(\mathrm{mg} \mathrm{cm}^{-2} \mathrm{~h}^{-1}\right)\end{array}$ & $\begin{array}{l}I E_{\mathrm{ML}} \\
(\%)\end{array}$ & $\begin{array}{c}C R \\
\left(\mathrm{mg} \mathrm{cm}^{-2} \mathrm{~h}^{-1}\right)\end{array}$ & $\begin{array}{l}I E_{\mathrm{ML}} \\
(\%)\end{array}$ \\
\hline \multirow[t]{5}{*}{30} & Blank & 1.0260 & - & 1.0260 & - \\
\hline & 200 & 0.1831 & 82.1 & 0.1300 & 87.3 \\
\hline & 300 & 0.1687 & 83.6 & 0.1180 & 88.5 \\
\hline & 400 & 0.1472 & 85.6 & 0.0999 & 90.3 \\
\hline & 500 & 0.1239 & 87.9 & 0.0796 & 92.2 \\
\hline 40 & Blank & 1.4170 & - & 1.4170 & - \\
\hline
\end{tabular}
various concentrations of SBPMA and DBBPB at different temperatures 


\begin{tabular}{cccccc}
\hline & 200 & 0.2800 & 80.2 & 0.2083 & 85.3 \\
& 300 & 0.2614 & 81.5 & 0.1881 & 86.7 \\
& 400 & 0.2345 & 83.4 & 0.1648 & 88.3 \\
$50 \quad 500$ & 0.2091 & 85.2 & 0.1382 & 90.2 \\
& Blank & 2.0400 & - & 2.0400 & - \\
& 200 & 0.4459 & 78.1 & 0.3436 & 83.2 \\
& 300 & 0.4116 & 79.8 & 0.3119 & 84.7 \\
& 400 & 0.3722 & 81.8 & 0.2691 & 86.8 \\
60 & 500 & 0.3237 & 84.1 & 0.2205 & 89.2 \\
& Blank & 2.733 & - & 2.733 & - \\
& 200 & 0.6996 & 74.4 & 0.5643 & 79.4 \\
& 300 & 0.6568 & 76.0 & 0.5192 & 81.0 \\
& 400 & 0.5858 & 78.6 & 0.4510 & 83.5 \\
& 500 & 0.5106 & 81.3 & 0.3732 & 86.3 \\
\hline
\end{tabular}

\subsection{Effect of temperature}

The effect of temperature on $C R$ and $I E_{\mathrm{ML}}(\%)$ was studied in $0.5 \mathrm{M} \mathrm{H}_{2} \mathrm{SO}_{4}$ in the temperature range of $30-60{ }^{\circ} \mathrm{C}$ in the absence and presence of different concentrations of inhibitors (Table 1). The inhibition efficiencies were found to decrease with increasing temperature from $30-60{ }^{\circ} \mathrm{C}$. It may be explained with desorption of adsorbed inhibitor on the MS surface. This proves that the inhibition occurs through the adsorption of the inhibitors on the metal surface, and desorption is aided by increase in temperature. The activation parameters for the corrosion process were calculated from the Arrhenius plot according to the following equation:

$$
C R=k \exp ^{-E a / R T}
$$

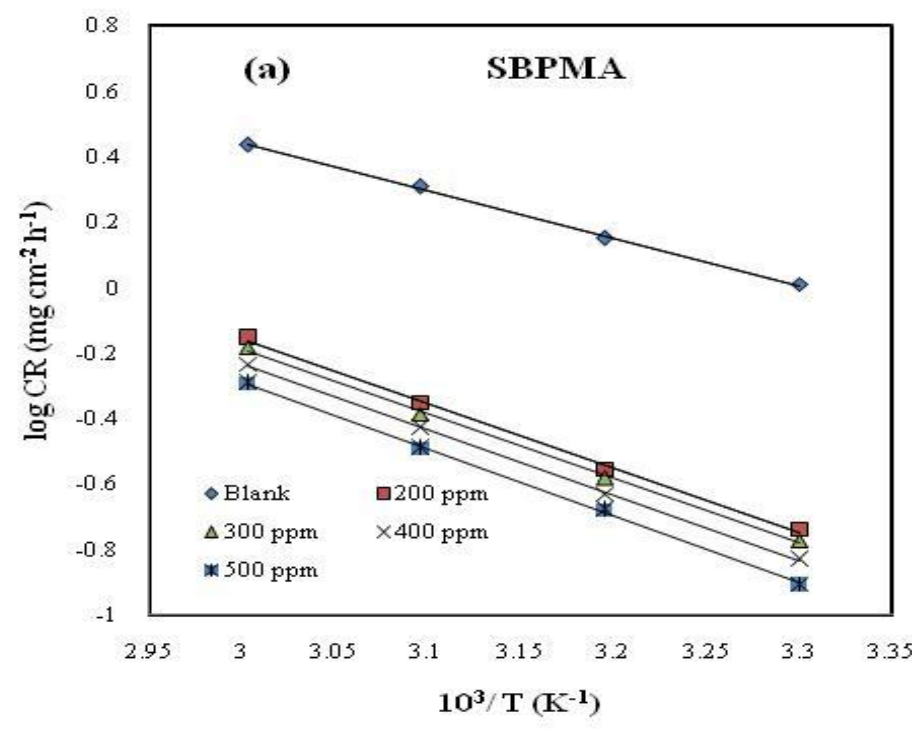

(5)

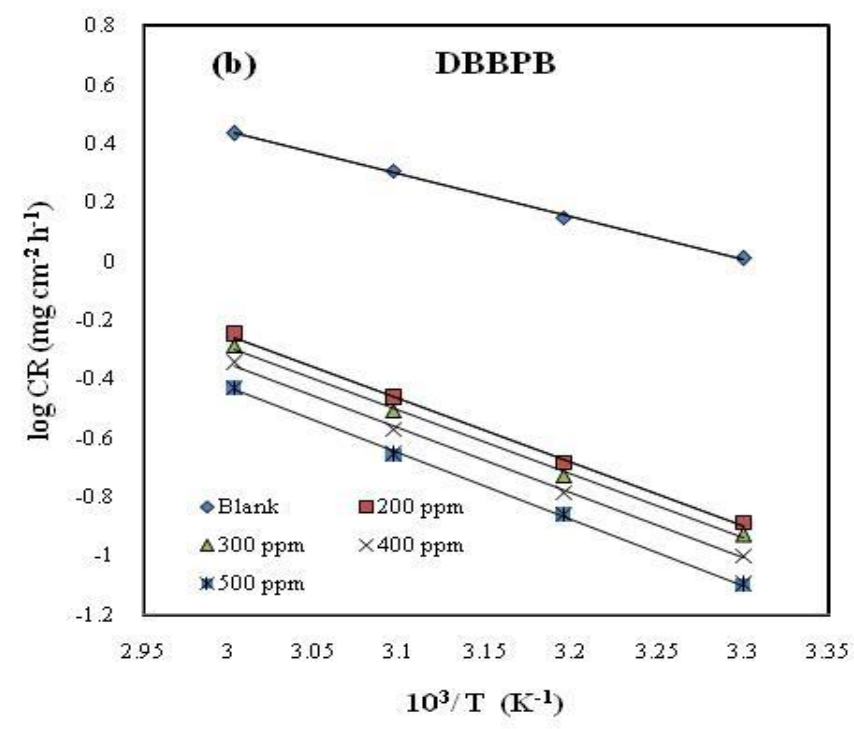

Fig. 2. Plot of $\log C R$ versus $1 / T$ for (a) SBPMA and (b) DBBPB 

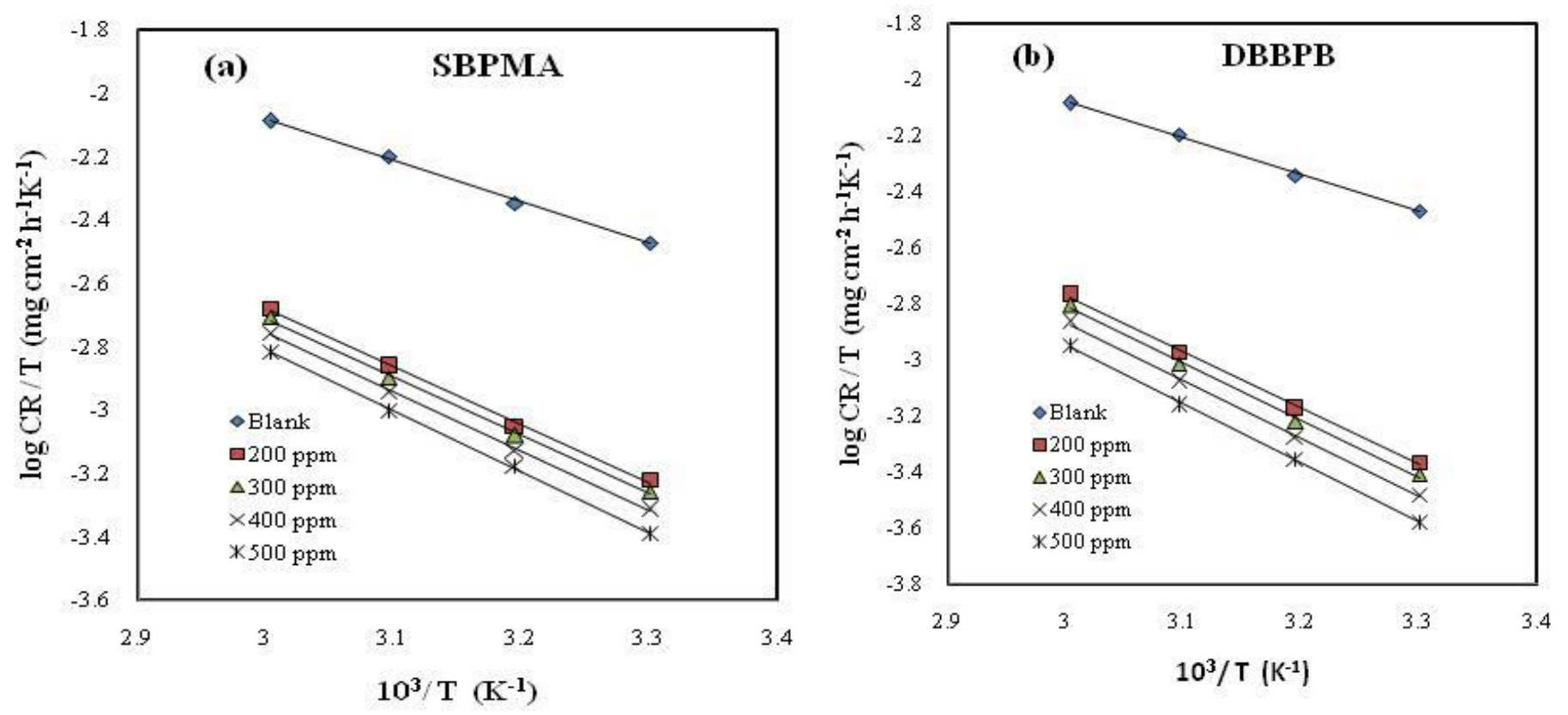

Fig. 3. Alternative Arrhenius plots for MS dissolution in $0.5 \mathrm{M} \mathrm{H}_{2} \mathrm{SO}_{4}$ medium in the absence and presence of (a) SBPMA and (b) DBBPB.

where $E_{a}$ is the activation energy, $k$ is the frequency factor, $T$ is the absolute temperature and $R$ is the universal gas constant. The values of $E_{a}$ for MS in $0.5 \mathrm{M} \mathrm{H}_{2} \mathrm{SO}_{4}$ without and with various concentrations of inhibitors are obtained from the slope of the plot of $\log C R$ versus $1 / T$ (Fig. 2) and are shown in Table 2. Inspection of Table 2 revealed that, the activation energy increasees in the presence of inhibitors, which indicated physical adsorption process (electrostatic) in the first stage [30]. The activation energy rises with increasing inhibitors concentration, suggesting the strong adsorption of inhibitor molecules at the metal surface [31].

An alternative Arrhenius plots of log $C R / T$ versus $1 / T$ (Fig. 3) for MS dissolution in $0.5 \mathrm{M} \mathrm{H}_{2} \mathrm{SO}_{4}$ medium in the absence and presence of different concentrations of SBPMA and DBBPB were used to calculate the values of activation thermodynamic parameters such as enthalpy of activation $\left(\Delta H_{\mathrm{a}}\right)$ and entropy of activation $\left(\Delta S_{\mathrm{a}}\right)$ using the relation (6)

$$
C R=\frac{R T}{N h} \exp \left(\frac{\Delta S_{a}}{R}\right) \exp \left(\frac{-\Delta H_{\mathbb{R}}}{R T}\right)
$$

where $R$ is the Universal gas constant, $T$ is the absolute temperature, $N$ is the Avogadro's number, $h$ is Planks constant The values of $\Delta H_{\mathrm{a}}$ and $\Delta S_{\mathrm{a}}$ were obtained from the slope and intercept of the above plot, and presented in Table 2. The obtained $\Delta H_{a}$ values are in good agreement with those calculated from the equation (7),

$$
\Delta H_{a}=E_{a}-R T
$$

The positive values of enthalpy of activation in the absence and presence of inhibitors indicate an endothermic nature of MS dissolution process [32]. The entropy of activation values are less negative in the presence of the inhibitors compare to free acid solutions, this suggests that an increase in randomness occurred while moving from reactants to the activated complex [33]. 
Table 2: Values of activation parameters for $\mathrm{MS}$ in $0.5 \mathrm{M} \mathrm{H}_{2} \mathrm{SO}_{4}$ medium in the absence and presence of various concentrations of SBPMA and DBBPB

\begin{tabular}{|c|c|c|c|c|c|}
\hline Inhibitor & $\begin{array}{c}\text { C } \\
(\mathrm{ppm})\end{array}$ & $\begin{array}{c}E_{\mathrm{a}} \\
\left(\mathrm{kJ} \mathrm{mol}^{-1}\right)\end{array}$ & $\begin{array}{c}\Delta H_{\mathrm{a}} \\
\left(\mathrm{kJ} \mathrm{mol}^{-1}\right)\end{array}$ & $\begin{array}{c}\Delta H_{\mathrm{a}}=E_{\mathrm{a}}-R T(\mathrm{~kJ} \\
\left.\mathrm{mol}^{-1}\right)\end{array}$ & $\begin{array}{c}\Delta S_{\mathrm{a}} \\
\left(\mathrm{J} \mathrm{mol}^{-1} \mathrm{~K}^{-1}\right)\end{array}$ \\
\hline Blank & 0 & 27.7 & -25.1 & 25.2 & -197.6 \\
\hline \multirow[t]{4}{*}{ SBPMA } & 200 & 37.6 & -34.9 & 35.1 & -144.0 \\
\hline & 300 & 38.0 & -35.3 & 35.4 & -143.4 \\
\hline & 400 & 38.6 & -35.9 & 36.1 & -142.4 \\
\hline & 500 & 39.3 & -36.7 & 36.8 & -141.3 \\
\hline \multirow[t]{4}{*}{ DBBPB } & 200 & 41.1 & -38.5 & 38.6 & -135.3 \\
\hline & 300 & 41.5 & -38.8 & 39.0 & -134.9 \\
\hline & 400 & 42.0 & -39.4 & 39.5 & -134.4 \\
\hline & 500 & 42.7 & -40.1 & 40.2 & -133.7 \\
\hline
\end{tabular}

\subsection{Adsorption isotherm}

The adsorption isotherm can give important information about the interaction of the inhibitor molecules and the metal surface. The adsorption of inhibitor molecules from aqueous solution is a quasi-substitution process, and was found to be highly $\mathrm{pH}$ dependent [34]. The surface protection of $\mathrm{MS}$ depends upon how the inhibitor molecule will adsorbed on the metal surface, and also ionization and polarization of molecules [35]. The degree of surface coverage $(\theta)$ as function of concentration $(\mathrm{C})$ of the inhibitor was studied graphically by fitting it to various adsorption isotherms to find the best adsorption isotherm. The Langmuir adsorption isotherm model was proposed since equilibrium adsorption of inhibitors was found to obey this adsorption isotherm model on MS in $0.5 \mathrm{M} \mathrm{H}_{2} \mathrm{SO}_{4}$ medium. According to this adsorption isotherm, $\theta$ is related to the inhibitor concentration, $C$ and adsorption equilibrium constant $K_{\text {ads }}$ through the following expression:

$$
C_{\theta}=\frac{1}{K_{\text {ads }}}+C
$$

The surface coverage was tested graphically by fitting a suitable adsorption isotherm. In these cases the plots of $C / \theta$ versus $C$ (Fig. 4) yield straight lines with the linear correlation coefficient $\left(R^{2}\right)$ values close to unity, which suggests that the adsorption of SBPMA and DBBPB in $0.5 \mathrm{M} \mathrm{H}_{2} \mathrm{SO}_{4}$ medium on MS surface obeys the Langmuir isotherm model. The free energy of adsorption was calculated using the following relation:

$$
\Delta G_{a d s}^{a}=-2.303 R T \log 55.5 K_{a d s}
$$

where $R$ is the universal gas constant, $T$ is the absolute temperature, $K_{\text {ads }}$ is the equilibrium constant for adsorptiondesorption process and 55.5 is the molar concentration of water in solution $\left(\mathrm{molL}^{-1}\right)$. The adsorption thermodynamic parameters such as enthalpy of adsorption $\left(\Delta H^{0}\right.$ ads $)$ and entropy of adsorption $\left(\Delta S^{\circ}\right.$ ads $)$ were obtained from the slope and intercept of the plot of log $K_{\text {ads }}$ versus $1 / \mathrm{T}$ (Fig. 5) using the equation (10).

$$
\log K_{\text {ads }}=\frac{1}{2.303}\left(-\frac{\Delta H_{\text {od }}^{\infty}}{R T}\right)+\left(\frac{\Delta s_{\text {odi }}^{\circ}}{R}\right)
$$

The calculated values of $K_{\text {ads }}, \Delta H^{\circ}$ ads, $\Delta G^{\circ}$ ads and $\Delta S^{\circ}$ ads over the temperature range of $30-60{ }^{\circ} \mathrm{C}$ are recorded in Table 3. The negative values of $\Delta G^{\circ}$ ads indicate the spontaneous adsorption of inhibitors on the MS surface [36]. In the present study, $\Delta G^{\circ}$ ads values for SBPMA and DBBPB are found to be in the range -36.62 to $-38.96 \mathrm{~kJ} \mathrm{~mol}^{-1}$ and -37.02 to $39.30 \mathrm{~kJ} \mathrm{~mol}^{-1}$, respectively indicating that the adsorption is more physisorption than chemisorption [37- 40]. 
Table 3: Thermodynamic parameters for adsorption of SBPMA and DBBPB on MS in $0.5 \mathrm{M} \mathrm{H}_{2} \mathrm{SO}_{4}$ at different temperatures

\begin{tabular}{|c|c|c|c|c|c|c|}
\hline Inhibitor & $\begin{array}{c}\mathrm{T} \\
\left({ }^{\circ} \mathrm{C}\right)\end{array}$ & $\mathbf{R}^{2}$ & Slope & $\begin{array}{c}\Delta G_{\text {ads }}^{\circ} \\
\left(\mathrm{kJ} \mathrm{mol}^{-1}\right)\end{array}$ & $\begin{array}{c}\Delta H^{\circ} \text { ads } \\
\left(\mathrm{kJ} \mathrm{mol}^{-1}\right)\end{array}$ & $\begin{array}{c}\Delta S^{\circ} \text { ads } \\
\left(\mathrm{J} \mathrm{mol}^{-1} \mathrm{~K}^{-1}\right)\end{array}$ \\
\hline \multirow[t]{4}{*}{ SBPMA } & 30 & 0.999 & 1.083 & -36.6 & & \\
\hline & 40 & 0.999 & 1.123 & -37.6 & 1.35 & 6.1 \\
\hline & 50 & 0.999 & 1.128 & -38.5 & & \\
\hline & 60 & 0.998 & 1.152 & -39.0 & & \\
\hline \multirow[t]{4}{*}{ DBBPB } & 30 & 0.999 & 1.043 & -37.0 & & \\
\hline & 40 & 0.999 & 1.065 & -38.2 & 1.58 & 5.5 \\
\hline & 50 & 0.999 & 1.067 & -38.8 & & \\
\hline & 60 & 0.998 & 1.089 & -39.3 & & \\
\hline
\end{tabular}
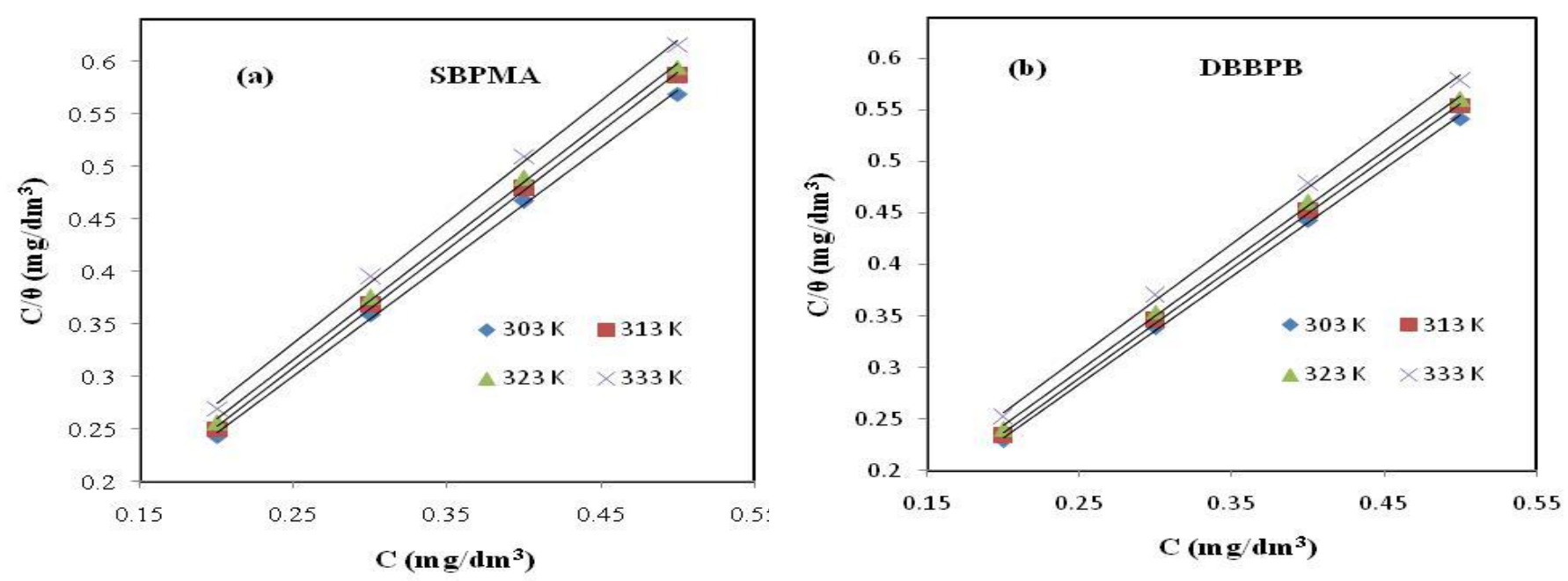

Fig. 4. Langmuir's adsorption isotherm plots for the adsorption of (a) SBPMA and (b) DBBPB in $0.5 \mathrm{M}$ H2SO4 on MS surface at different temperature

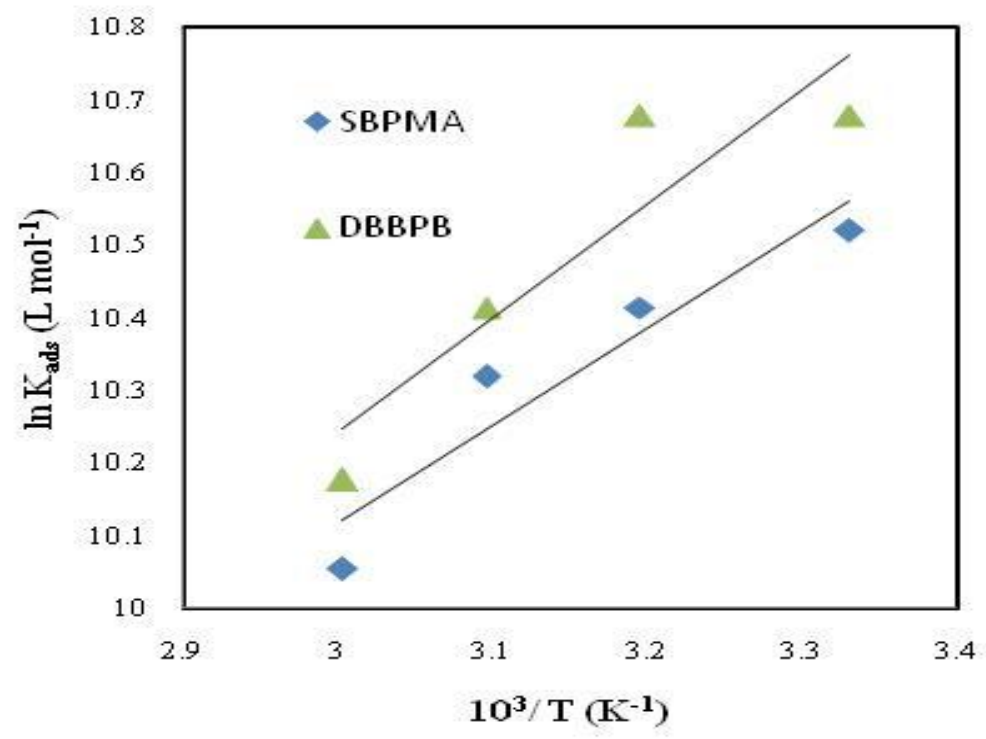

Fig. 5. Plot of InKads versus $1 / T$ for SBPMA and DBBPB 


\subsection{FTIR spectral studies}

FTIR spectra were recorded to understand the interaction of inhibitor molecules with the metal surface. Figs. $6 a$ and $7 \mathrm{a}$ show the FTIR spectra of pure SBPMA and DBBPB, and Figs. $6 \mathrm{~b}$ and $7 \mathrm{~b}$ represent the FTIR spectra of the scratched samples obtained from the metal surfaces after corrosion experiments. It was found that peaks in the spectrum of pure compounds were changed in the spectrum of scratched samples. The azomethine group stretching frequencies for pure SBPMA and DBBPB were found to be at 1615 and $1626 \mathrm{~cm}^{-1}$, respectively. In the FTIR spectra of scratched samples, the stretching frequencies of the azomethine group were found to be disappeared in both SBPMA and DBBPB confirming that the azomethine groups are involved in the complex formation with the metal.
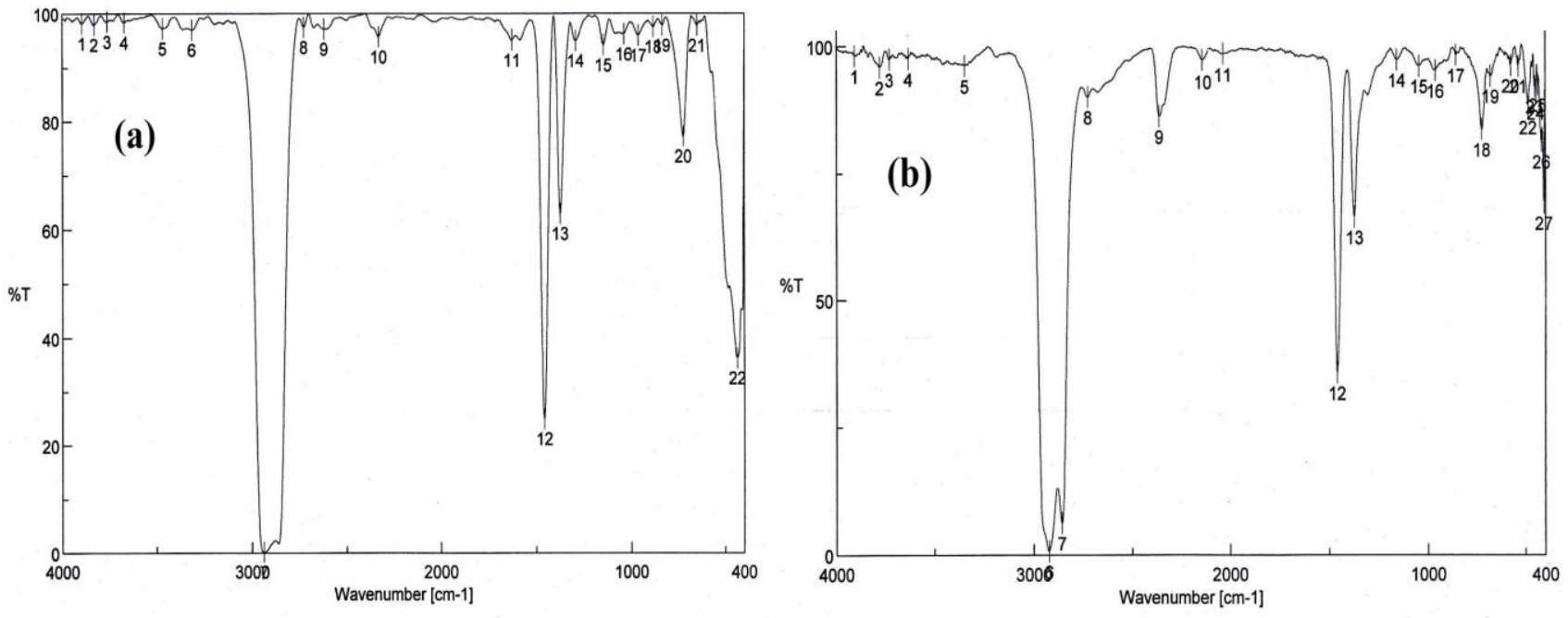

Fig. 6. FTIR spectra of (a) SBPMA and (b) scratched MS surface adsorbed SBPMA film.
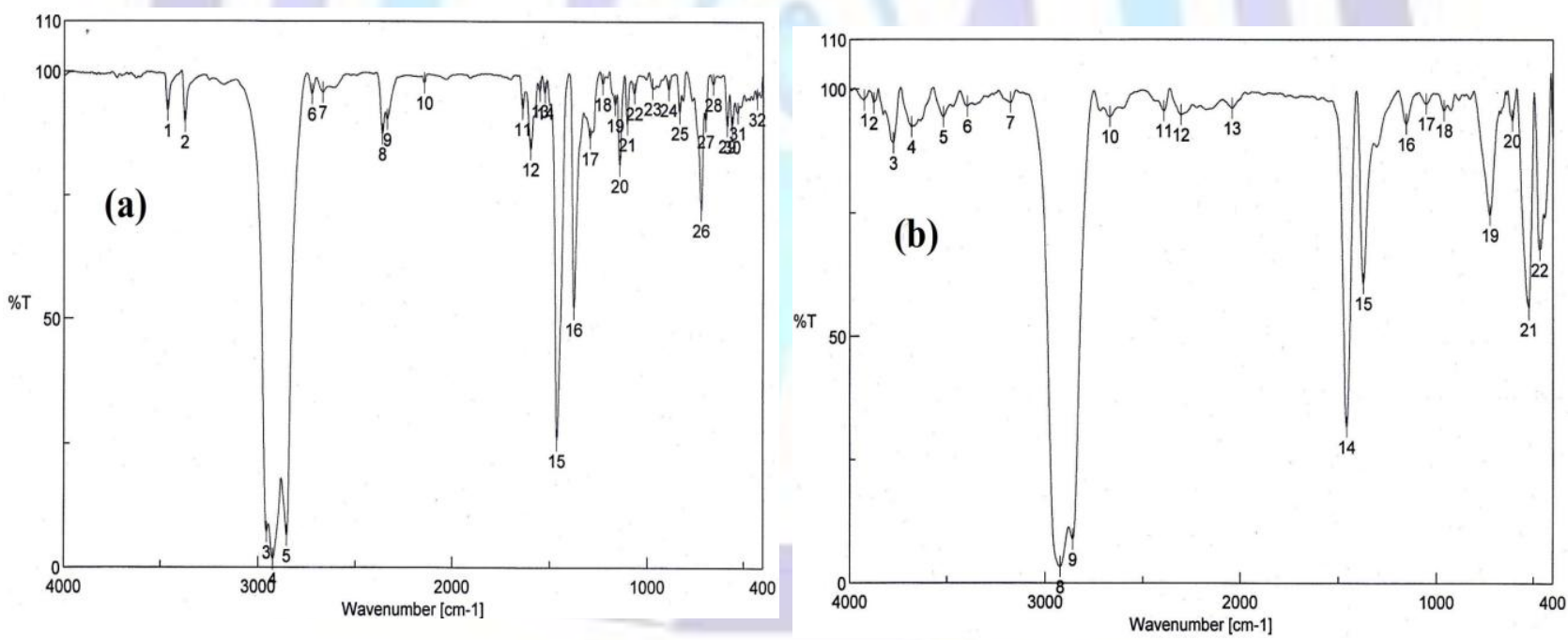

Fig. 7. FTIR spectra of (a) DBBPB and (b) scratched MS surface adsorbed DBBPB film.

\subsection{Potentiodynamic polarization measurements}

Polarization measurements were carried out to know the kinetics of anodic and cathodic reactions. Fig. 8 reveals the polarization curves for $\mathrm{MS}$ in $0.5 \mathrm{M} \mathrm{H}_{2} \mathrm{SO}_{4}$ in the absence and presence of different concentrations of SBPMA and DBBPB. Inspection of Fig. 8 revealed that the addition of inhibitors hindered the acid attack on the MS electrode. In all the cases, the addition of inhibitors reduces both anodic and cathodic current densities indicating that these inhibitors exhibit cathodic and anodic inhibition effects, hence they are relatively mixed type of corrosion inhibitors [41, 42].

Table 4 clearly highlights that there is a gradual decrease in the corrosion potential and corrosion current values as the inhibitor's concentration was raised from $200-500$ ppm. The values associated with electrochemical polarization measurements such as corrosion current density $\left(i_{\text {corr }}\right)$, corrosion potential $\left(E_{\text {corr }}\right)$ and inhibition efficiency $\left(I E_{\mathrm{p}} \%\right)$ were determined from the polarization plots are given in Table 4 . The values of corrosion current densities were obtained by extrapolating the current-potential lines to the corresponding corrosion potentials. It is evident that $I E_{\mathrm{P}}(\%)$ increases with inhibitors concentration, and protection action of SBPMA and DBBPB can be attributed to the electron density of the azomethine $(-\mathrm{C}=\mathrm{N}-)$ group and this electron density varies with the substituents in the inhibitor molecules. The imine 
nitrogen can donate the lone pair of electrons to the metal surface more easily and hence reduce the corrosion rate. The higher IEP (\%) of DBBPB compare to that of SBPMA, can probably be explained on the basis of the additional functional groups and also the nature of the hetero atoms the inhibitor molecule contain in its structure.
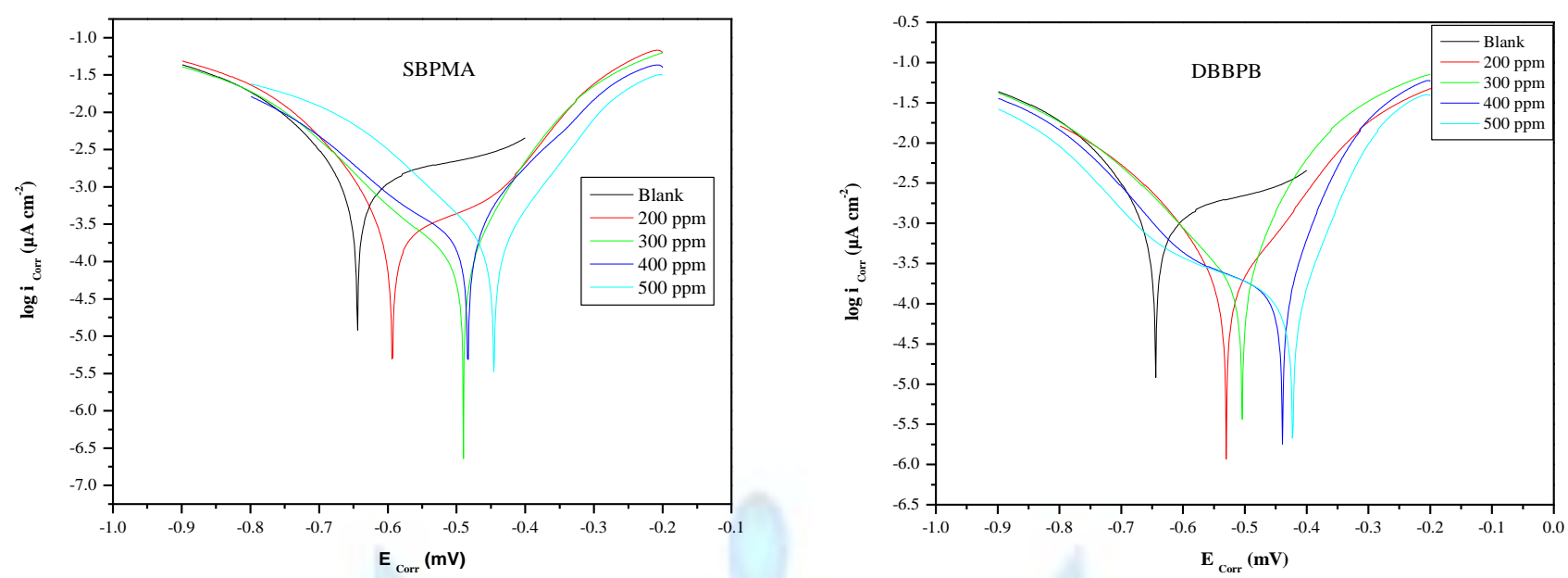

Fig. 8 Polarization curves of MS in $0.5 \mathrm{M} \mathrm{H}_{2} \mathrm{SO}_{4}$ in the presence of different concentrations of SBPMA and DBBPB.
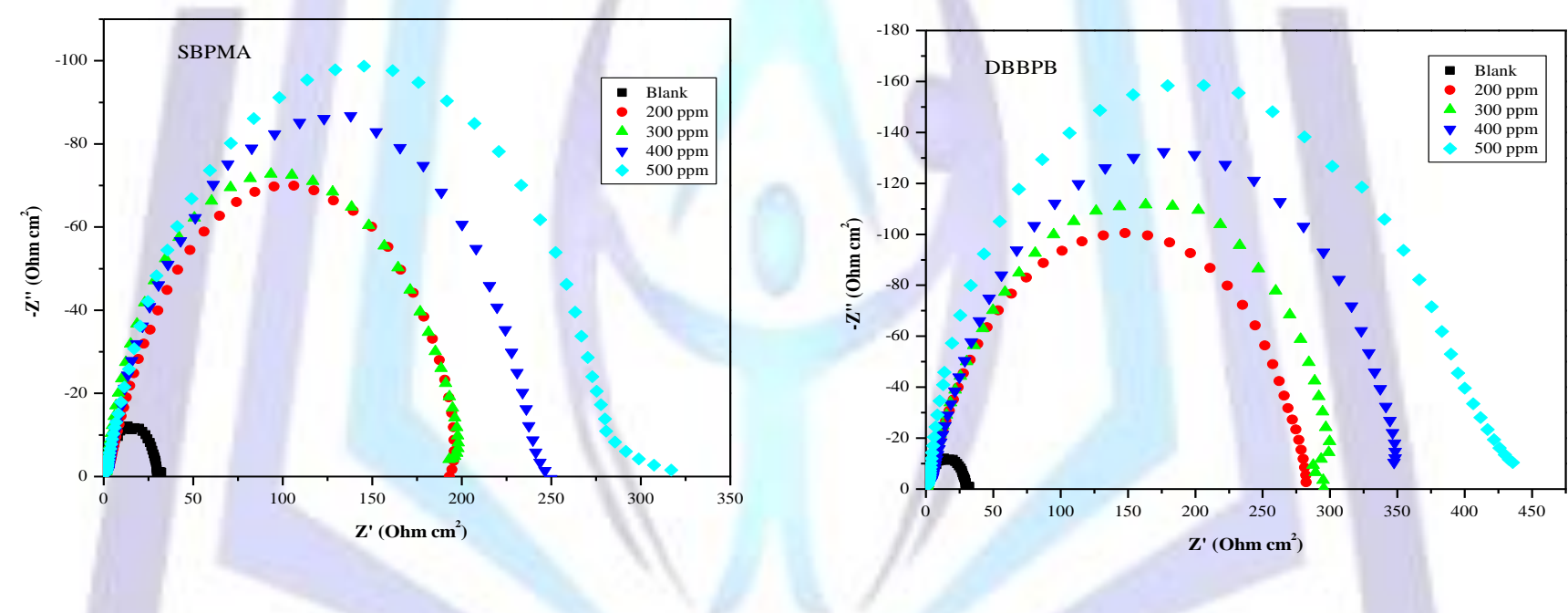

Fig. 9 Nyquist plots for MS in $0.5 \mathrm{M} \mathrm{H}_{2} \mathrm{SO}_{4}$ in the presence of different concentrations of SBPMA and DBBPB.

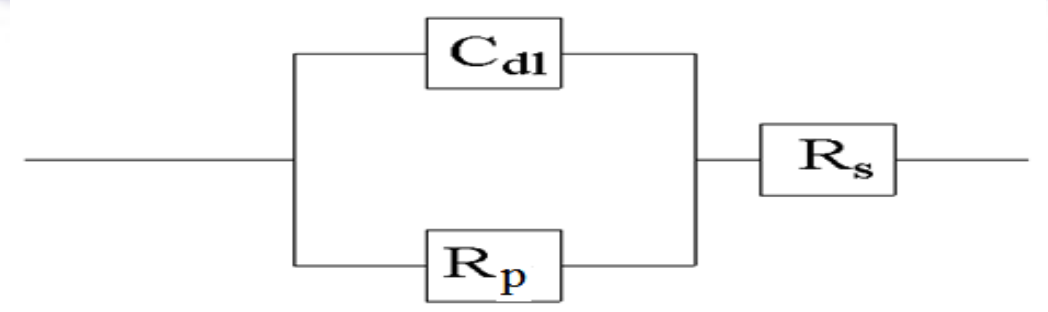

Fig. 10 Equivalent circuit used to fit the impedance spectra. 
Table 4: Polarization parameters and corresponding inhibition efficiency $\left(I E_{\mathrm{P}}\right)$ for the corrosion of the MS in $0.5 \mathrm{M}$ $\mathrm{H}_{2} \mathrm{SO}_{4}$ without and with various concentrations of SBPMA and DBBPB

\begin{tabular}{ccccc}
\hline Inhibitor & $\begin{array}{c}\boldsymbol{C} \\
(\mathbf{p p m})\end{array}$ & $\begin{array}{c}-E_{\text {corr }} \\
(\mathbf{m V})\end{array}$ & $\begin{array}{c}\boldsymbol{i}_{\text {corr }} \\
\left(\mu \mathrm{A} \mathrm{cm} \mathbf{c}^{-2}\right)\end{array}$ & $\begin{array}{c}I E_{\mathrm{p}} \\
(\%)\end{array}$ \\
\hline Blank & 0 & & 1444 & - \\
SBPMA & 200 & 0.644 & 260.1 & 82.0 \\
& 300 & 0.594 & 228.0 & 84.2 \\
& 400 & 0.510 & 215.7 & 85.1 \\
& 500 & 0.483 & 176.4 & 87.8 \\
DBBPB & 0.446 & & 87.7 \\
& & & & 88.6 \\
& 200 & & 177.1 & 90.3 \\
& 300 & 0.530 & 164.9 & 92.8 \\
\hline
\end{tabular}

\subsection{Electrochemical impedance spectroscopy}

The Nyquist plots for MS in $0.5 \mathrm{M} \mathrm{H}_{2} \mathrm{SO}_{4}$ solution without and with different concentrations of SBPMA and DBBPB are presented in Fig. 9. The electrochemical impedance parameters derived from the Nyquist plots and $I E_{E I S}(\%)$ are listed in Table 5. From the plots it is clear that the impedance response of MS in uninhibited acid solution has significantly changed after the addition of inhibitors to the corrosive solution. This indicates that the impedance of the inhibited metal has increased with increasing concentration of inhibitors. The measured impedance data were based upon the equivalent circuit given in the Fig. 10 , consists of double layer capacitance $\left(C_{\mathrm{dll}}\right)$, polarization resistance $\left(R_{\mathrm{p}}\right)$ and solution resistance $\left(R_{\mathrm{s}}\right)$.

It was observable that, the increase in the $R_{\mathrm{p}}$ values in the presence of different concentrations of SBPMA and DBBPB indicate the reduction in the MS corrosion rate with the formation of adsorbed protective film on the metal-solution interface $[43,44]$. When the concentration is raised from $200-500 \mathrm{ppm}$, there was a gradual increase in the diameter of semi-circle of the Nyquist plot reflecting increasing $R_{p}$ values from 27.81 to 234.5 and $363.7 \Omega \mathrm{cm}^{2}$ for SBPMA and DBBPB, respectively, which indicates the adsorption of inhibitors on the metal surface. The double layer capacitance $\left(C_{\mathrm{dl}}\right)$ values were decreased due to decrease in local dielectric constant and / or increase in the thickness of the electrical double layer, indicating that the inhibitor molecules adsorbed at the metal-solution interface [45, 46]. Decrease in the surface area [47] and imperfections of the metal surface may also be the reason for decrease of $C_{\mathrm{dl}}$ values. Addition of inhibitors provided lower $C_{\mathrm{dl}}$ values because of the replacement of water molecules by inhibitor molecules at the electrode surface [48].

\subsection{EDX analysis}

EDX spectra were used to determine the elements present on MS surface before and after exposure to the inhibitor solution. Fig. 11a is the EDX spectrum of abraded MS sample and it is notable that the peak of oxygen is absent which confirm the absence of air formed oxide film. However, for inhibited solutions (Figs 11b and 11c) additional lines characteristic for the existence of $\mathrm{N}, \mathrm{O}$ and $\mathrm{S}$ (due to the $\mathrm{N}, \mathrm{O}$ and $\mathrm{S}$ atoms of the SBPMA and DBBPB) in the EDX spectra are obtained. These data showed that the $\mathrm{N}, \mathrm{O}$ and $\mathrm{S}$ atom of inhibitors are involved in bonding with the MS electrode. 
Table 5: Impedance parameters for the corrosion of MS in $0.5 \mathrm{M} \mathrm{H}_{2} \mathrm{SO}_{4}$ in the absence and presence of different concentrations of SBPMA and DBBPB

\begin{tabular}{|c|c|c|c|c|}
\hline Inhibitor & $\begin{array}{c}C \\
(\mathrm{ppm})\end{array}$ & $\begin{array}{c}R_{\mathrm{P}} \\
\left(\Omega \mathrm{cm}^{2}\right)\end{array}$ & $\begin{array}{c}C_{\mathrm{dl}} \\
(\mu \mathrm{F} \mathrm{cm})\end{array}$ & $\begin{array}{c}I E_{\mathrm{EIS}} \\
(\%)\end{array}$ \\
\hline Blank & 0 & 27.81 & 320.2 & --- \\
\hline \multirow[t]{4}{*}{ SBPMA } & 200 & 157.5 & 75.90 & 82.3 \\
\hline & 300 & 169.5 & 63.63 & 83.6 \\
\hline & 400 & 196.5 & 49.66 & 85.8 \\
\hline & 500 & 234.5 & 44.78 & 88.1 \\
\hline \multirow[t]{4}{*}{ DBBPB } & 200 & 223.9 & 65.27 & 87.6 \\
\hline & 300 & 243.2 & 55.65 & 88.6 \\
\hline & 400 & 290.3 & 41.81 & 90.4 \\
\hline & 500 & 363.7 & 38.98 & 92.4 \\
\hline
\end{tabular}

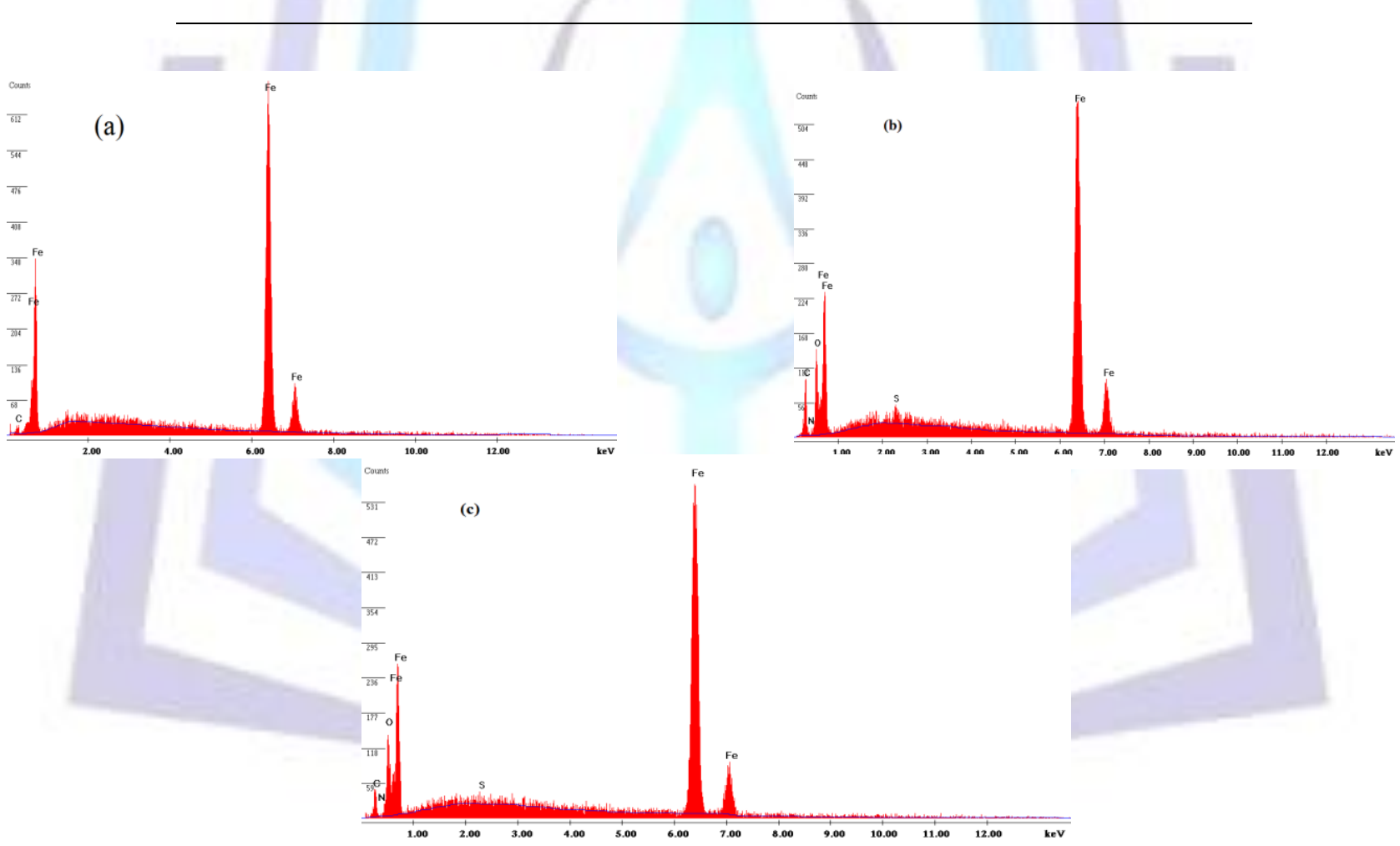

Fig. 11 EDX spectra of (a) polished MS surface (b) MS in 500 ppm SBPMA and (c) MS in 500 ppm DBBPB.

\subsection{SEM analysis}

The surface morphology of MS surface due to corrosion process was confirmed by the SEM images of the abraded and corroded MS surface in the absence and presence of inhibitors (Figs. 12a-12d). Fig. 12a represents the SEM image for abraded MS surface. Fig. 12b is the SEM image of MS surface in $0.5 \mathrm{M} \mathrm{H}_{2} \mathrm{SO}_{4}$ without inhibitor. It was found that the corroded MS surface contains large number of pits. However, SEM images of MS surface in the presence of inhibitors (Figs. 12c and 12d) were observed to be smoother than that of MS surface in $0.5 \mathrm{M} \mathrm{H}_{2} \mathrm{SO}_{4}$ alone. These observations reveal that, the inhibitors form protective layer on the MS surface which prevents the attack of acid as well as the dissolution of MS by forming surface adsorbed layer and thereby reducing the corrosion rate. 

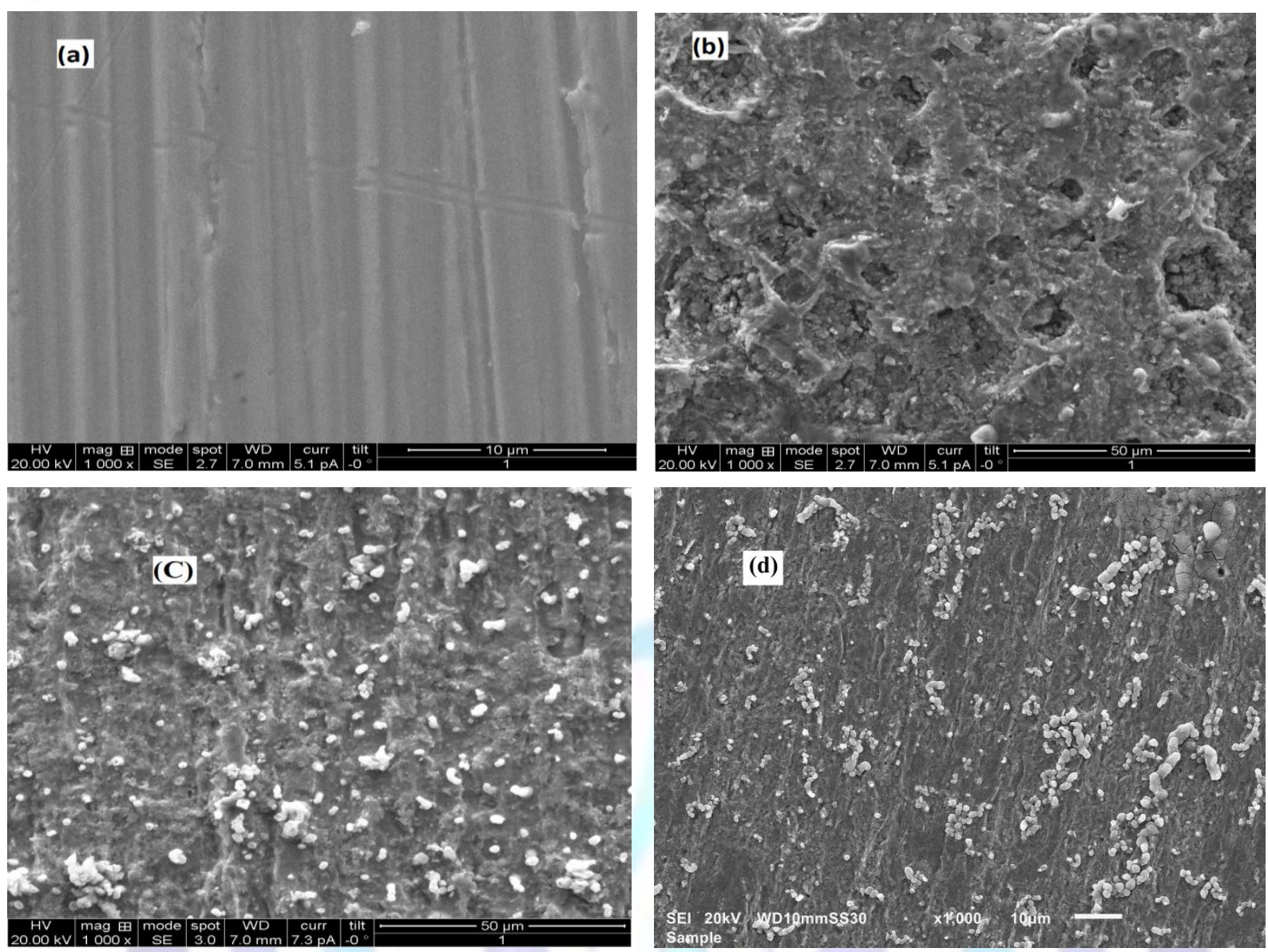

Fig. 12 SEM images of (a) polished MS surface (b) MS in $0.5 \mathrm{M} \mathrm{H}_{2} \mathrm{SO}_{4}$ (c) MS in 500 ppm SBPMA and (d) MS in 500 ppm DBBPB.

\section{CONCLUSIONS}

1. The synthesized dapsone derivatives showed good inhibition efficiency for the corrosion of $\mathrm{MS}$ in $0.5 \mathrm{M} \mathrm{H}_{2} \mathrm{SO}_{4}$ solutions and the inhibition efficiency was found to be time, temperature and concentration dependent.

2. Langmuir adsorption isotherm was found to be the best description for the studied inhibitors, and the negative values of Gibbs free energy of adsorption indicate that the adsorption of inhibitors is more physisorption than chemisorption process.

3. The inhibition efficiency of DBBPB was found to be higher than that of SBPMA and the inhibition efficiencies determined by mass loss, potentiodynamic polarization and EIS methods are in good agreement with each other.

4. FTIR spectra, scanning electron microscopy (SEM) and energy dispersive X-ray spectroscopy (EDX) were performed to characterize the passive film on the metal surface.

5. The chemical structures of SBPMA and DBBPB are correlated with their inhibition efficiency.

\section{ACKNOWLEDGEMENT}

One of the authors (MPC) is grateful to University of Mysore, Mysore for awarding SRF to carry out the research work.

\section{REFERENCES}

[1] N. N. Nathan, Corrosion Inhibitors (National Association of Corrosion Engineering's, Houston, Texus, 1997)

[2] G. Trabanelli, Corrosion 47 (1991) 410.

[3] M. A. Arena, A. Conde and J. De Damborenea, Corros Sci 44 (2002) 511.

[4] E. Cano, P. Pinila, J. L. Pole and J. M. Bastidas, Mater Corros 54 (2003) 222.

[5] C. Dong-Jin, K. Youg-Wook and K. Jung-Gu, Mater Corros 52 (2001) 697. 
[6] G. Moretti, F. Guidi and G. Grion, Corros Sci 46 (2004) 387.

[7] S. A. Abd El-Maksoud, Int J Electrochem Sci 3 (2008) 528.

[8] M. A. Quraishi and R. Sardar, Mater Chem Phy 78 (2003) 425.

[9] M. S. Sachin, S. Bilgic and H. Yilmaz, Appl Sur Sci 195 (2002) 1-7.

[10] M. Abdulla, M. Al-Agez and A. S. Fouda, Int J Electrochem Sci 4 (2009) 336.

[11] M. Bouklah, A. Aouniti, B. Hammouti, M. Benkaddour, M. Lagrenee and F. Bentiss, Prog Org Coat 51 (2004) 118.

[12] F. Bentiss, M. Traisnel, H. Vezin, H. F. Hildebrand and M. Lagrenee, Corros Sci 46 (2004) 2781.

[13] H. Wang, R. Liu and Xin, Corros Sci 46 (2004) 2455.

[14] M. Karakus, M. Sahin and S. Bilgic, Mater Chem Phy 92 (2005) 565.

[15] A. Afidah, E. Rahim, J. Rocca, M.J. Steinmetz, R.A. Kassim and M. Sani Ibrahim, Corros Sci 49 (2007) 402.

[16] W. Li, Q. He, C. Pei and B. Hou, Electrochim Acta 52 (2007) 6386.

[17] S. Sankarapapavinasam, F. Pushpanaden and M. F. Ahmed, Corros Sci 48 (2006) 608.

[18] M. Lebrini, F. Robert and C. Roos, Inter J Corros, Vol. 2013, 2013 Article ID 139798, pp.1-13.

[19] B. I. Ita, O. U. Abakedi and V. N. Osabor, Global Advanced Research Journal of Engineering, Technology and Innovation 2 (2013) 084.

[20] B. I. Ita, O. E. Offiong, O. U. Abakedi and N. O. Alobi, J Sci Ind Res 66 (2007) 919.

[21] E. E. Ebenso, T. Arslan, F. Kandemirli, I. Love, C. Ogretir, M. Saracoglu and S. A. Umoren, Int J Quantum Chem 110 (2010) 2614.

[22] R. T. Loto, C. A. Loto and A. P. I. Popoola, J Mater Envir Sci 3 (2012) 885.

[23] G. Bereket, E. Hur and C. Ogretir, J Mol Struct (Theochem) 578 (2002) 79.

[24] Lin Wang, Corros Sci 48 (2006) 608.

[25] L. Herrag, A. Chetouani, S. Elkadiri, B. Hammouti and A. Aouniti, Portu Electrochim Acta 26 (2008) 211.

[26] B. Zerga, B. Hammouti, M. Ebn Touhami, R. Touir, M. Taleb, M. Sfaira, M. Bennajeh and I. Forssal, Int J Electrochem Sci 7 (2012) 471.

[27] O. I. Sizaya and A. P. Andrushko, Prot Metals 40 (2004)164.

[28] F. Bentiss, M. Lagrenee, M. Traisnel and J.C. Hornez, Corros Sci 41 (1999) 789.

[29] A. Singh, A. K. Singh and M. A. Quraishi, The Open Electrochemistry Journal 2 (2010) 43.

[30] H. Ashassi-Sorkhabi, B. Shaabani, D. Seifzadeh, Appl Surf Sci 239 (2005) 154.

[31] A.Y. Musa, A. A. H. Kadhum, A. B. Mohamad, A. Razak Daud, M. S. Takriff, S. K. Kamarudin A, Corros Sci 51 (2009) 2393.

[32] M. Abdallah, E. A. Heal and A. S. Fouda, Corros Sci 48 (2006) 1639.

[33] M. Bouklah, B. Hammouti, M. Lagrenee and F. Bentiss. Corros Sci 48 (2006) 2831.

[34] A. K. Bhattacharya, T. K. Naiya, S. N. Mandal and S. K. Das, Chem Eng J 137 (2008) 529.

[35] S. A. M. Refaey, F. Taha and A. M. Abd El-Malak, Int J Electrochem Sci 1 (2006) 80.

[36] Xianghong Li, Shuduan Deng, Hui Fu, Corros Sci 53 (2011) 3241.

[37] M. Bouklah, B. Hammouti, M. Lagrenee and F. Bentiss, Corros Sci 48 (2006) 2470.

[38] F. M. Bayoumi and W. A. Ghanem, Mater Lett 59 (2005) 3806.

[39] A. Yurt, A. Balaban, S. Ustun Kandemir, G. Bereket and B. Erk, Mater Chem Phy 85 (2004) 420.

[40] X. Li, S. Deng, H. Fu and T. Li, Electrochim Acta 54 (2009) 4089.

[41] M. Lebrini, F. Bentiss, H. Vezin, M. Lagrenee, Appl Surf Sci 252 (2005) 950.

[42] A. Y. Musa, A. A. H. Kadhum, A. B. Mohamad, M. S. Takriff, A. R. Daud and S. K. Kamarudin, Corros Sci 52 (2010) 526.

[43] F. Bentiss, M. Lebrini, M. Langrenee, M. Traisnel, A. Elfarouk and H. Vezin, Electrochim Acta 52 (2007) 6865.

[44] F. El-Taib Heakal, A. A. Ghoneim and A. M. Fekry, J Appl Electrochem 37 (2007) 405.

[45] M. Lebrini, F. Bentiss, H. Vezin and M. Lagrene, Corros Sci 48 (2006) 1279. 
[46] S. K. Shukla and M. A. Quaraishi, Corros Sci 52 (2010) 314.

[47] F. Bentiss, M. Traisnel and M. Lagrenee, Corros Sci 42 (2000) 127.

[48] K. Parameswari, S. Chaitra, C. Nusrath Unnisa and A. Selvaraj, J App Sci Res 6 (2010) 1100. 